\title{
RELATIVIDAD LINGÜÍSTICA, GRAMÁTICAS DE GÉNERO Y LENGUAJE INCLUSIVO: ALGUNAS CONSIDERACIONES
}

\author{
Linguistic Relativity, \\ Gender Grammar and Inclusive Language: \\ Some Considerations
}

\author{
Silvia Carolina Scotto ${ }^{a}$ \\ https://orcid.org/0000-0002-2013-8539 \\ carolina.scotto@unc.edu.ar \\ DiAna InÉs PÉRez ${ }^{b, c}$ \\ https://orcid.org/0000-0002-6185-7986 \\ dperez@filo.uba.ar \\ ${ }^{a}$ Instituto de Humanidades - Facultad de Filosofía y Humanidades - Universidad \\ Nacional de Córdoba - Consejo Nacional de Investigaciones Científicas y Técnicas, \\ Córdoba, Argentina. \\ ${ }^{b}$ Instituto de Investigaciones Filosóficas - Sociedad Argentina de Análisis Filosófico - \\ Consejo Nacional de Investigaciones Científicas y Técnicas, Buenos Aires, Argentina \\ ${ }^{c}$ Universidad de Buenos Aires, Argentina
}

\section{Resumen}

En este artículo examinaremos un caso de aplicación de la hipótesis de la relatividad lingüística (HRL): la influencia del género gramatical de las lenguas sobre la cognición o el pensamiento de los hablantes. Dado que las lenguas difieren tanto en sus repertorios léxicos como sobre todo en sus gramáticas de género para referir a las personas, a otras entidades animadas e incluso a entidades inanimadas, nuestro propósito será, en primer lugar, revisar la evidencia experimental reciente que avalaría la HRL en este dominio, al comprobar una variedad de impactos cognitivos y psicológicos, variables según las lenguas de los hablantes. En particular, identificaremos cuáles son los "efectos relativistas" en el caso de los rasgos morfosintácticos de las lenguas con carga de género, y en relación con la universalización del género masculino. Sobre la base de la evaluación realizada e incorporando los aportes de los estudios de "género y lenguaje" de los enfoques feministas, concluiremos señalando de qué diversas maneras es viable e importante promover usos inclusivos del lenguaje e incluso cambios más profundos hacia un lenguaje inclusivo, con especial referencia al español.

Palabras clave: Hipótesis de la relatividad lingüística; Gramáticas de género; Carga de género; Genérico masculino; Lenguaje inclusivo. 


\begin{abstract}
In this paper, we examine a case of application of the hypothesis of linguistic relativity (HLR): the influence of the grammatical gender of languages on the cognition or thinking of speakers. Since languages differ both in their lexical repertoires, but, specially, in their gender grammars to refer to people, other animated beings and even inanimate entities, our purpose will be, first, to review the recent experimental evidence that would support the HLR on this domain, because they verify a variety of cognitive and psychological impacts, variable according to the languages of the speakers. In particular, we will identify what are the "relativist effects" in the case of morphosyntactic features of gender-loaded languages and in a relation to the universalization of the male gender. Based on the evaluation carried out and incorporating the contributions of "gender and language" studies of feminist approaches, we will conclude by pointing out in what ways it is viable and important to promote inclusive uses of language and even deeper changes towards an inclusive language, with special reference to Spanish.
\end{abstract}

Key words: Hypothesis of Linguistic Relativity; Gender Grammar; Gender-loaded Language; Generic Male; Inclusive Language.

\title{
1. Introducción
}

La hipótesis de la relatividad lingüística (en adelante: HRL), conocida como "la hipótesis Sapir-Whorf"1, afirma que el lenguaje que hablamos afecta o influye en algún grado y en diferentes aspectos sobre nuestro pensamiento o cognición no lingüística (Sapir, 1929; Whorf, 1956; Lucy, 1992; Gentner \& Goldin-Meadow, 2003). En este contexto "lenguaje" refiere a los principios de categorización y a las reglas que definen la estructura gramatical de las lenguas naturales ${ }^{2}$, y "pensamiento" refiere a todos los procesos cognitivos ${ }^{3}$, excluidos

${ }^{1}$ Se la ha rebautizado, intentando una mayor justicia histórica, "la hipótesis Vico-Herder-(Hamman)-Humboldt-(Boas)-Sapir-Whorf” (cfr. Everett, 2013, p. 11). Incluimos a Hamman y Boas, siguiendo la reconstrucción que ofrece Everett sobre sus influencias respectivas.

${ }^{2}$ Utilizaremos indistintamente lenguaje y lengua para hacer referencia a los lenguajes naturales (vgr. el japonés, el español, etc.) y no a los rasgos estructurales hipotéticamente universales que pudieran compartir entre ellos. Es decir, no nos referiremos en este trabajo al lenguaje como una facultad cognitiva o un conjunto de principios y reglas formales compartidos por todas las lenguas, sino que adoptamos el "enfoque basado en el uso", que concibe al lenguaje como un sistema comunicativo dinámico, multimodal y semióticamente heterogéneo (véase Scotto, 2020).

${ }^{3}$ Asumimos una noción amplia de cognición, que incluye además de capacidades como la percepción, la atención, la memoria, etc., otros rasgos psicológicos (afectivos, volitivos, actitudinales, conductuales, etc.). Aunque alguna distinción entre "cognitivo" y "psicológico" es pertinente en este contexto, utilizaremos ambos conceptos para 
aquellos que están específicamente involucrados en el procesamiento lingüístico (Beller et al., 2015). Sin embargo, es claro que la distinción misma es problemática de establecer, por lo cual la cuestión podría ser más apropiadamente reformulada de la siguiente manera: “¿cuán estrechamente interconectados están el pensamiento lingüístico y otros tipos de pensamiento?" (Everett, 2013, p. 35) y más precisamente aún: ¿en qué medida y de qué maneras el lenguaje influye sobre sobre cada uno de los diversos procesos cognitivos? (Zlatev \& Blomberg, 2015).

La HRL ha cobrado nueva vida en las últimas décadas, como lo reflejan los trabajos experimentales realizados por los psicolingüistas testeando varias hipótesis más específicas sobre distintos dominios semánticos. En este contexto, se ha suscitado una interesante convergencia teórica entre los resultados de las investigaciones psicolingüísticas en los que se constatarían efectos cognitivos de las gramáticas de género de las lenguas y los estudios feministas acerca del papel de las lenguas en reproducir y perpetuar actitudes y estereotipos sexistas.

En efecto, desde que hace 70 años Simone de Beauvoir afirmara en $E l$ segundo sexo que "no se nace mujer, se llega a serlo" (Beauvoir, 1998), la filosofía feminista ha complejizado la distinción femeninomasculino que persiste en la gramática de muchas lenguas. En los estudios feministas y en general en las ciencias sociales encontramos desarrollada una distinción entre sexo y género, reservando el término "sexo" para referir a las diferencias biológicas entre los seres humanos ${ }^{4}$, en tanto que la palabra "género" se utiliza para hacer referencia a la dimensión social que acompaña usualmente a las distinciones biológicas. ${ }^{5}$ En la actualidad las distinciones que el feminismo traza en lo relativo al género son muchas. Por un lado, contamos con la noción de "identidad de género" que remite a la autopercepción que cada persona tiene de sí misma, por lo tanto, se trata de una categorización puramente subjetiva. En segundo lugar, la "expresión de género" está relacionada con la manera como nos presentamos ante los demás, i.e. qué género queremos que los demás usen para referirse a nosotros. En tercer lugar, la expresión "roles de género" atañe a las actividades y

abarcar las diferentes influencias del lenguaje alcanzadas por la HRL.

${ }^{4}$ Como es sabido, hoy está biológicamente establecido que no hay dos sexos, ni anatómica ni genéticamente (Fausto-Sterling, 1993, 2000; Maffía, 2003), por lo que desde el punto de vista estrictamente biológico no podemos afirmar que haya dos categorías exhaustivas y excluyentes con las cuales categorizar a todos los miembros de la especie humana. Así, por ejemplo, hay personas intersex.

${ }^{5}$ Véase Lamas (1986), donde se explicita la historia de la incorporación de esta categoría en las ciencias sociales. 
características usualmente asignadas a hombres y mujeres en nuestra sociedad. Y finalmente, la "orientación sexual" se define en términos del tipo de personas que son el objeto del deseo sexual (del mismo sexo, del sexo opuesto, de ambos sexos).

La cuestión es aún más compleja de lo que parece hasta aquí, dado que el supuesto básico que está detrás de todas estas distinciones podría ser incorrecto. Parece inadecuado utilizar una distinción dicotómica ("binaria") para clasificar a las personas: no hay por qué pensar que cada persona debería encasillarse como mujer o varón (-cis 0 -trans) ${ }^{6}$, ni para sí misma, ni para los demás; hay personas que no tienen una orientación sexual en la que su deseo se orienta sistemáticamente hacia un mismo conjunto de personas de un sexo/género determinado; y podría sostenerse que la mayoría de (¿todos?) los roles sociales pueden ser realizados por cualquier ser humano, más allá de qué etiqueta tenga $o$ no tenga de acuerdo a cada una de las distinciones mencionadas arriba.

Lo cierto es que hasta no hace mucho tiempo estas distinciones no se explicitaban, dado que socialmente se encontraban "alineadas" (y, consecuentemente, cualquier caso que se apartara de este alineamiento era considerado una patología). Así, se partía de la idea de que biológicamente hablando hay solo dos sexos, a los que socialmente se les asociaba un género diferente. Por ejemplo, las mujeres -biológicamente hablando-no podían verse a sí mismas sino como mujeres, debían presentarse ante los demás para ser reconocidas como mujeres, debían asumir los roles asignados a las mujeres en la sociedad a la que pertenecían, y debían tener como orientación sexual la femenina, i.e. desear sexualmente solo hombres. Y lo mismo mutatis mutandis en el caso de los hombres. Nótese que la forma misma de presentar esta concatenación de alineamientos es normativa, no descriptiva. Cualquier persona o conducta que se alejara de este patrón era considerada patológica hasta no hace mucho tiempo atrás: la homosexualidad (i.e. la orientación sexual hacia personas del mismo sexo) fue eliminada en 1973 del DSM-IV y la OMS la eliminó como trastorno mental el 17 de mayo de 1990. Y muchos casos de diferencias con el alineamiento mencionado siguen siendo consideradas patológicas: hasta hoy el DSM vigente (DSM-V) sigue considerando la transexualidad como una patología denominada "disforia de género".

Consideramos que en el contexto de la convergencia señalada entre los estudios psicolingüísticos y los estudios feministas surgen nuevas preguntas y reflexiones que podrían contribuir al debate actual acerca

\footnotetext{
${ }^{6}$ Se entiende por personas trans a aquellas que asumen un género diferente de aquel asignado al nacer, y por personas cis a aquellas en las que ambos coinciden.
} 
de la viabilidad de promover no solo distintas estrategias inclusivas de uso lingüístico sino también reformas más profundas de la gramática de las lenguas, así como a ponderar sus efectos positivos. Nuestro plan de trabajo es el siguiente. En primer lugar, presentaremos las variedades de la HRL actualmente en discusión, identificando diferentes tipos de influencia del lenguaje sobre la cognición/pensamiento, en distintos dominios semánticos (2.). En segundo lugar, examinaremos los recursos o las gramáticas de género que las diferentes lenguas utilizan para referir a entidades, tanto sexuadas como no sexuadas, especialmente en las lenguas con carga de género (3.). En seguida, relevaremos algunos resultados experimentales realizados sobre lenguas que difieren claramente en sus recursos para realizar dichas referencias en los que se comprueban diversos impactos cognitivos en los hablantes (4.). Nos referiremos, luego, a la universalización del género masculino, teniendo en cuenta los efectos constatados en estudios empíricos en los que se comparan usos del genérico masculino vis-a-vis usos más inclusivos del lenguaje (5.). Finalmente, sobre la base de los estudios empíricos revisados que prueban efectos relativistas referidos al género en muchas lenguas, y en nuestra lengua en particular, mencionaremos brevemente diversas formas de concebir el lenguaje inclusivo, y sostendremos la conveniencia de adoptarlo (6.).

\section{La hipótesis de la relatividad lingüística: fundamentos y variedades}

Una prestigiosa tradición filosófica ha concebido al lenguaje como un mero medio de codificación de los pensamientos, los cuales estarían constituidos por componentes conceptuales y reglas para combinarlos que se consideran pre-existentes e independientes del lenguaje. Esta es la concepción del lenguaje como un código (Acero, 1998). De acuerdo a ella, el lenguaje es, sobre todo, un medio de expresión de los pensamientos. La HRL desafió esa concepción, al asumir, primero, que las lenguas naturales pueden diferir entre sí tanto en los significados vehiculizados por medio de las palabras como en las reglas gramaticales y construcciones sintácticas a las que recurren; y afirmando, luego, que estas diferencias influyen o afectan las formas en las que los hablantes de las distintas lenguas piensan y actúan. Ahora bien, si el lenguaje natural puede influir en el modo cómo los hablantes perciben y conceptualizan el mundo, es decir, influir sobre el pensamiento, entonces los hablantes de diferentes lenguajes piensan (al menos, en alguna medida) de maneras diferentes (Wolff \& Holmes, 2011). El lenguaje ya “...no es solo 
una herramienta comunicativa, sino que es, también, una herramienta representacional" (Gomila, 2012, p. 20). Esta hipótesis, elaborada por Sapir primero y sobre todo por Whorf después (entre los años 40 y 50 del siglo pasado) ha sido "revitalizada" (Reines \& Prinz, 2009) a partir de mediados de los años 90 (Lucy, 1992; Gumperz \& Levinson, 1996), tanto en la investigación lingüística comparada como en la reflexión teórica, sobre todo en las ciencias cognitivas.

Sin avalar la HRL, Roman Jakobson (1971) formuló un núcleo importante de la idea contenida en ella: "...los lenguajes difieren esencialmente en lo que ellos deben expresar y no en lo que pueden expresar" (p. 264). Este hecho podría llevar a hablantes de diferentes lenguajes a prestar más atención a aquellas dimensiones del significado que están obligatoriamente expresadas en su lenguaje (“...naturalmente la atención de los hablantes y oyentes nativos estará constantemente focalizada en tales ítems en la medida que están compulsivamente en su código verbal" (p. 264-265) y, en ese sentido, son "estructuralmente imperativas". Del mismo modo, llevaría a prestar menos atención a los ítems que son opcionales o solo "preferencias acerca del uso" (Lucy, 2016). Por otra parte, e independientemente de la posible existencia de rasgos universales al lenguaje humano, se acepta actualmente que las lenguas naturales están estructuradas de maneras muy diferentes en todos los niveles: fonológico, morfológico, léxico, sintáctico y semántico (Evans \& Levinson, 2009). Por ejemplo, los inventarios o repertorios léxicos, es decir, las distinciones que en distintos dominios semánticos están codificadas en palabras, varían dramáticamente entre las lenguas, i.e., acerca del color, el movimiento, las emociones y otros estados mentales, las partes del cuerpo, el espacio, la causalidad, etc. (Wolff \& Malt, 2010; Everett, 2013). Las lenguas también difieren en una variedad de componentes y roles gramaticales, establecidos mediante reglas fonológicas, morfológicas y sintácticas. Algunos ejemplos que ilustran la diversidad mencionada podrían ofrecerlo los pronombres personales: el pronombre de segunda persona en lengua española distingue el trato formal ("usted") e informal ("tú" o "vos") en singular y también en plural ("vosotros" vs. "ustedes"), en contraste con el inglés; también el pronombre de primera persona del plural en lengua tamil, distingue entre un "nosotros" inclusivo que incluye al hablante y al interlocutor y quizás a otros y un "nosotros" exclusivo que no incluye al interlocutor, en contraste con el español;

\footnotetext{
${ }^{7}$ Jakobson se manifiestó expresamente en contra de la dependencia de la cognición respecto del lenguaje, aunque reconoció que en ciertos usos del lenguaje (mitológicos, poéticos) las diferencias gramaticales entre las lenguas, p.e. en sus gramáticas de género, plantean problemas difíciles de resolver para la traducción.
} 
incluso hay lenguas como el aymara, el guaraní y el quechua, que tienen más de tres personas gramaticales (Mannheim, 1982; Bossong, 2009).

El descrédito de la variante determinista de la HRL, i.e. la tesis radical -también atribuida a Whorf- según la cual las lenguas determinan enteramente los esquemas conceptuales y los modos de pensamiento de las comunidades que los utilizan ${ }^{8}$ y el predominio de la tradición "universalista" en la lingüística y en las ciencias cognitivas en general (Gumperz \& Levinson, 1996), que favoreció una visión acerca de los rasgos estructurales del lenguaje humano indiferente a la diversidad de las lenguas naturales, tuvo una de sus expresiones más explícitas en Pinker (1999), quien desechó cualquier variedad de relativismo como "enteramente errónea". Pinker dedicó una crítica in extenso sobre todo al determinismo, cuestionando la frágil evidencia psicológica con la cual Whorf pretendió justificarlo. No obstante, como señala acertadamente Thierry (2016), de la insustentabilidad del determinismo no se sigue que pensamiento y lenguaje sean independientes. Pero Pinker también criticó los "exiguos resultados" que las investigaciones de laboratorio acumularon durante los 30 años siguientes, las cuales, según su valoración, apenas intentaron poner a prueba “...versiones 'descafeinadas' de la hipótesis de Whorf” (p. 68). Sus objeciones más importantes, sin embargo, se dirigieron a algunas limitaciones inherentes al diseño de las pruebas experimentales, objetando, por ejemplo, que estuvieran basadas exclusivamente en la realización de pruebas verbales, ya que incurrían en circularidad al presuponer (y no explicar) que las diferencias lingüísticas eran responsables de diferencias en las respectivas maneras de pensar. Del mismo modo señaló la necesidad de clarificar las instrucciones en las pruebas experimentales, identificar con claridad las capacidades cognitivas involucradas, etc. Todos estos señalamientos metodológicos fueron tenidos en cuenta en los diseños experimentales más recientes que dan apoyo a la HRL, como veremos más adelante.

El giro que ha vuelto a revitalizar el interés por la HRL ha sido posible por un "cambio de clima intelectual" (Gumperz \& Levinson, 1996, p. 3) en varias disciplinas científicas, sobre todo en la psicología y la lingüística, marcado por un desplazamiento hacia enfoques que

\footnotetext{
${ }^{8}$ Diversos fenómenos cognitivos desacreditaron el determinismo lingüístico, tales como la posibilidad de comprender expresiones lingüísticas ambiguas, la experiencia de no poder expresar en palabras un pensamiento, la existencia de nuevos conceptos carentes de expresión léxica, así como la variada actividad cognitiva de niños y animales sin lenguaje. Ahora bien, la falta de apoyatura empírica puso por mucho tiempo en una situación de fragilidad no solo al determinismo lingüístico sino a la HRL en todas sus variedades (Reines \& Prinz, 2009).
} 
volvieron a prestar más atención a la diversidad lingüística y cultural frente a la búsqueda de rasgos comunes, de la cognición y/o el lenguaje. Tuvo el mismo impacto otro factor notable: el mayor conocimiento y disponibilidad de datos acerca de las aproximadamente 7000 diferentes lenguas del mundo, puesto que ha proporcionado fundamentos hasta hace relativamente poco tiempo no disponibles, acerca de la magnitud y la potencial relevancia teórica de la diversidad lingüística (Gumperz \& Levinson, 1996; Evans \& Levinson, 2009) $)^{9}$. Por otra parte, también debe distinguirse a la HRL de versiones "triviales" de la influencia del lenguaje en el pensamiento, que nadie negaría, pero que no son relevantes para ella. ${ }^{10}$ Así, dejando de lado la tesis fuerte del determinismo y la tesis trivial del relativismo, la HRL volvió a ser examinada como una hipótesis empíricamente plausible. ${ }^{11}$

En la literatura más reciente sobre el tema se denominan "efectos relativistas" a los diferentes tipos de influencia que el lenguaje, más propiamente ciertos rasgos de la lengua, léxicos y/o gramaticales, ejercen sobre la cognición no lingüística. En la literatura se pueden rastrear distintas clasificaciones del fenómeno de acuerdo a diferentes criterios. Lucy (1996), por ejemplo, distingue entre tres tipos de relatividad: "semiótica", "estructural" y "discursiva". La relatividad "semiótica" está referida al tipo de influencia específica que el lenguaje, en tanto un tipo de sistema semiótico en contraste con otros sistemas semióticos, ejerce sobre el pensamiento humano; ${ }^{12}$ la "estructural" refiere a "las

\footnotetext{
${ }^{9}$ Los recientes estudios relativistas en distintos dominios semánticos incorporaron cada vez más información de lenguas muy diferentes, más allá de las pertenecientes a la familia indoeuropea (véase Everett, 2013).

${ }^{10}$ Pinker (2007, pp. 126-28) distingue, por ejemplo, cinco formas de "whorfianismo banal". Reines y Prinz (2009) denominan "whorfianismo trivial" a la tesis sobre la influencia efímera del lenguaje limitada a los procesos ligados al uso efectivo. Bloom y Keil (2001) también se refieren a versiones "no interesantes" de la relatividad.

${ }^{11}$ Respecto al determinismo, muchas veces se ha interpretado que es solo la versión más fuerte de la tesis de la influencia del lenguaje en el pensamiento, en un continuo de otras posibles relaciones más laxas entre cognición y lenguaje. Sin embargo, como veremos, las relaciones entre cognición y lenguaje pueden ser de tipos muy diferentes, y además podrían manifestarse en forma combinada, es decir, no son excluyentes entre sí (Zlatev \& Blomberg, 2016), por lo cual sería erróneo verlas simplificadamente solo como expresiones más fuertes o más atenuadas en un continuo (Wolff \& Holmes, 2011).

${ }^{12}$ Lucy señala la relevancia de identificar esta variedad de relatividad "semiótica", dado que podría limitar la importancia o incluso desacreditar la HRL en relación con las lenguas. Lucy también señala que una seria investigación sobre la HRL depende, en parte, de adoptar una u otra visión acerca de los rasgos específicos del lenguaje humano y su impacto en la cognición.
} 
características de los lenguajes específicos (que) tienen un impacto sobre el pensamiento o conducta de quienes lo hablan" (Lucy, 1996, p. 41). El relativismo "discursivo", finalmente, es la influencia que ejercen ciertos modos habituales de uso del lenguaje por parte de ciertos grupos dentro de una misma lengua e incluso dentro de una misma comunidad de habla. ${ }^{13}$ Las investigaciones sobre relativismo lingüístico han estado limitadas a lo que Lucy denomina "relativismo estructural".

Una taxonomía más fina, aunque compatible con la anterior (Everett, 2013), respecto de las posibles maneras en las que el lenguaje influye sobre la cognición es la propuesta por Wolff y Holmes (2011), quienes distinguen las influencias que ocurren antes de usar el lenguaje, durante su uso y después de ocurrido.

(a) La primera es capturada por la noción de "pensar para hablar" (thinking for speaking) propuesta por Slobin (1996). Refiere al hecho de que los recursos específicos de cada lengua obligan a los hablantes que se preparan para hablar, a prestar atención a la información que deberá ser obligadamente codificada: i.e., los verbos en inglés deben registrar el momento en el que ocurrió el evento que se narra, en turco deben especificar si fueron o no presenciados por el narrador; en ruso, si quien realizó la acción narrada es varón o mujer (Boroditsky, Schmidt \& Phillips 2003). Las reglas del género gramatical son también obligatorias para los hablantes de las lenguas que las poseen. Este vínculo debería extenderse, más allá de la producción del habla, a la comprensión del habla de otros (Gomila, 2012). Aunque para algunos este tipo de influencia no sería un caso de relatividad lingüística (Reines \& Prinz, 2009), para otros debe tomarse en cuenta, en tanto afecta los patrones atencionales y la memoria. ${ }^{14}$

${ }^{13}$ En "Language and Woman's Place", un clásico en los estudios sobre género y lenguaje, Robin Lakoff (1973) exploró la tesis de que las diferencias en las formas de usar el lenguaje reflejaban pero también fortalecían una posición subordinada de las mujeres respecto a los hombres (Eckert \& McConnell-Ginet, 2003). Ese enfoque generó una línea de investigaciones sobre las relaciones entre género y lenguaje. Leaper (2014), entre otros, refiere estudios realizados sobre algunas formas de habla en la interacción social que serían más características en las mujeres, tales como la talkativeness (locuacidad), self-disclosure (hablar de sí mismo), elgossip (chisme), ciertas modalidades de turn-taking (alternancia de turnos) y el gusto por la conversación. El examen de estos usos comunicativos del lenguaje, ya sea como usos típicos o como parte del estereotipo femenino y la lingüística folk (véase Talbot, 2003), deben tomarse en cuenta en relación al debate sobre la HRL y el lenguaje inclusivo, aunque requieren contar con un corpus de datos lingüísticos de una muestra de lenguas más amplia que la actualmente disponible (Gygax et al., 2019). Estas prácticas discursivas convierten al género en el lenguaje en un fenómeno lingüístico complejo y multidimensional, no limitado a su manifestación a nivel formal de la lengua (Hellinger \& Bußmann, 2001).

${ }^{14}$ Un estudio de Papafragou et al. (2008), muestra los diferentes comportamientos 
Cuando la influencia del lenguaje ocurre durante los procesos cognitivos, se pueden diferenciar dos tipos de interacciones:

(b) El lenguaje actúa como entrometido (meddler): en este caso las representaciones lingüísticas se combinan y compiten con las no lingüísticas, interfiriendo o facilitando el pensamiento. El mismo experimento con hablantes del griego y del inglés mencionado en la nota 14, que involucra verbos relativos al movimiento, muestra diferentes patrones atencionales y memoria de eventos cuando los sujetos no tienen que describir esos eventos, sino solo pensar en ellos. Los términos de color podrían tener efectos en la capacidad para discriminar y categorizar los colores (Winawer et al., 2007) ${ }^{15} \mathrm{y}$, como veremos, el género asignado a un objeto en la lengua nativa es recordado por ese hablante aun cuando no tenga que hablar de él.

(c) El lenguaje actúa como potenciador (augmenter): en este caso, el lenguaje posibilitaría ciertas formas de pensamiento. Este rol puede apreciarse "...cuando un lenguaje realmente carece de las palabras para un dominio particular que es considerado central para el funcionamiento cognitivo en nuestra propia cultura o viceversa" (Gordon, 2010, p. 199). El caso ha sido constatado en relación con la cognición numérica y el uso de números exactos, una capacidad dependiente de la habilidad lingüística, más precisamente, de la posesión de un léxico específico para los números exactos. Aunque es igual para sujetos que hablan diferentes lenguas, podría comprobarse un efecto relativista en el caso de los hablantes de una lengua que careciera de términos para números exactos -es decir, que poseyera solo sistemas asíllamados uno-dos-muchos (one-two-many) o de números aproximados, no recursivo, que se supone innato, y que apenas permite distinguir cantidades de manera aproximada o borrosa

de atención visual de hablantes del griego y del inglés, al describir eventos en movimiento: mientras los primeros siguen la dirección del movimiento, los segundos no. Los verbos en griego codifican no solo el tipo sino también la dirección del movimiento, por lo cual los hablantes prestan atención a ese aspecto de la acción a diferencia de los hablantes del inglés, que reservan esa información para otras palabras. Esta conducta es diferente cuando los hablantes no tienen que describir verbalmente esos eventos (cfr. Wolff \& Holmes, 2011).

15 En los últimos años, muchas pruebas experimentales lograron comprobar "efectos relativistas" en el procesamiento perceptual. Winawer et al. (2007) testearon hablantes del inglés y del ruso, dos lenguas que difieren en el vocabulario de color ("blue" en inglés corresponde en ruso a "golubóy", para azules más claros y "siniy", para azules más oscuros) y comprobaron un desempeño diferente en tareas de discriminación perceptual y categorización de muestras de color y en juicios de similaridad. Para una presentación detallada de la evolución de la investigación experimental sobre la HRL en relación con el léxico de colores en diversas lenguas, véase Gomila (2012, cap. 4 ). 
y unas pocas cantidades precisas (no más de 4). Este sería el caso de los hablantes de la lengua pirahã, una pequeña población monolingüe de la Amazonia. Los tests realizados muestran que los individuos no consiguen realizar tareas cognitivas que requieren la posesión de un sistema gramatical de números exactos y del respectivo vocabulario, dado que estos proporcionarían un medio indispensable para su conceptualización. ${ }^{16}$

Otros tipos de influencia ocurren después de que el lenguaje ha sido usado: se trata del impacto del uso de un lenguaje en el largo plazo, en tanto puede dirigir la atención habitual a propiedades específicas del mundo, incluso en contextos no lingüísticos, y podría inducir un modo de procesamiento, que puede persistir incluso independientemente de la realización de tareas lingüísticas. Así:

(d) El lenguaje actúa como foco (spotlight), puesto que hace más salientes ciertas propiedades del mundo codificadas en las lenguas y que son de uso obligatorio. Como veremos enseguida, el género gramatical ha probado ser un caso donde las lenguas con carga de género, esto es, aquellas que diferencian por el género a los sustantivos comunes referidos a todo tipo de entidades e imponen reglas de género para otras palabras asociadas, obligando a poner la atención sobre ellas, refuerzan ciertas asociaciones que dependen enteramente de esos rasgos, en contraste con las lenguas sin esa carga. También se constataría este efecto en el caso de los marcos de referencia espaciales (absoluto, intrínseco o egocéntrico), respecto a los verbos referidos a relaciones espaciales (ubicación y movimiento), y en los sistemas de categorización de objetos y sustancias (mediante sustantivos contables y no contables), rasgos en los cuales las lenguas también difieren.

Finalmente,

(e) El lenguaje actúa como inductor: la idea es que el uso habitual del lenguaje podría estimular ciertas maneras de conceptualizar la experiencia, evidenciadas, por ejemplo, al reaccionar ante ciertas imágenes orientadas vertical $\mathrm{u}$ horizontalmente y a describirlas de cierta manera (Wolff \& Holmes, 2011). Veremos que también en el caso del género gramatical, el lenguaje podría influir de este modo.

Ahora bien, no siempre es sencillo identificar cada uno de estos efectos, ya que a veces se solapan entre sí (Everett, 2013). Es momento

16 Los resultados con los hablantes del pirahã avalarían una variedad de determinismo más que de relativismo lingüístico, en tanto podrían explicar ya no el incremento de cierto tipo de cognición sino su condición de posibilidad (o imposibilidad). Sin embargo, son discutidos con distintos fundamentos. Para un examen de las interpretaciones encontradas sobre este caso, puede verse Gomila (2012) y Everett (2013), entre otros. 
de considerar los rasgos gramaticales que sirven para marcar el género o las gramáticas de género, en particular en las lenguas con mayor carga de género.

\section{Gramáticas de género en las lenguas}

Como dijimos, las lenguas difieren en los recursos que utilizan para expresar contenidos relativos a la clasificación de las personas y otras entidades. Para determinar tipologías entre ellas en lo referido al género gramatical se han utilizado diferentes criterios. Según la propuesta de Gygax et al. (2019), para abordar una investigación comparada rigurosa entre las lenguas, debería tomarse en cuenta la presencia de tres rasgos específicos de género: las diferencias morfosintácticas, el masculino genérico y las asimetrías en el léxico y en las expresiones referidas a mujeres y hombres. ${ }^{17}$ En este trabajo nos ocuparemos solo de los dos primeros, pero el tercer rasgo merece, al menos, un breve comentario.

Las asimetrías de género abarcan una variedad de tipos de expresiones codificadas en las lenguas, que reflejan maneras desiguales de tratar lingüísticamente a hombres y mujeres, tales como las formas de dirigirse a otras personas (address forms) ${ }^{18}$; las frases idiomáticas (frozen phrases $)^{19}$ y los proverbios, las expresiones insultantes o peyorativas (i.e. "mother-fucking", en inglés, y similares; "brujas" en español y similares), las metáforas ("sweetie", "honey" en inglés, "caramelito" en

${ }^{17}$ Para Kaufmann y Bohner (2014), sin embargo, el masculino genérico es la forma más sistemática de asimetría en las lenguas.

${ }^{18}$ Las lenguas difieren mucho respecto de los sistemas codificados para dirigirse a otras personas, algunos son muy simples como el inglés, otros son muy complejos como el japonés, aunque varían, a su vez, al interior de los diferentes grupos sociales y según los contextos. En muchas lenguas, por ejemplo el español, hay dos formas de dirigirse a las mujeres: "Señora" y "Señorita", destacando su estado civil, en tanto que hay una sola forma de dirigirse a los hombres: "Señor".

19 No debería menospreciarse el impacto cognitivo del llamado "lenguaje formulaico" (formulaic language) (frases hechas, proverbios, etc.) con contenidos sexistas, muy frecuentes en distintas lenguas, porque estas expresiones son aprendidas y procesadas como secuencias ya "congeladas", de una manera diferente a los ítems léxicos que son escogidos y combinados "creativamente" por los hablantes (véase Fernández Martín, 2011). Vgr., las expresiones "jefe de familia" vs. "ama de casa”, diferencian claramente los roles estereotípicos asignados a hombres y mujeres: uno refiere al sostén económico y el otro a quien lava los platos. Del mismo modo, frases hechas como "Los hombres no lloran", "Detrás de un gran hombre hay una gran mujer"; "Pórtate como una señorita"; "No hay quien la entienda", etc., ponen de manifiesto diferentes estereotipos sexistas. Un rico inventario de proverbios relativos a las mujeres en más de 150 países del mundo puede consultarse en Schipper (2010). 
español y otras metáforas comestibles referidas a las mujeres). También la ausencia de variantes femeninas o masculinas de ciertos términos (títulos, profesiones), y las asimetrías morfológicas en las palabras según el género ("poetisa" y "poeta", en español, o "Lehrerinnen" (maestra) y "Lehrer" (maestro) en alemán, entre otras (véase Hellinger \& Bußmann, 2001; Fernández Martín, 2011) ${ }^{20}$ En la medida que se trata de expresiones de uso muy frecuente en el lenguaje corriente, deberían ser incluidas en la evaluación de los efectos cognitivos y/o psicológicos que tienen sobre los hablantes (cfr. Gygax et al., 2019).

Las lenguas clasifican los sustantivos de acuerdo a diferentes rasgos semánticos: en algunas lenguas los sistemas clasificatorios son muy robustos, en otras se clasifican en apenas unas pocas categorías (Everett,2013). Entre ellas, algunas categorías incluyen las que están más o menos relacionadas con el sexo biológico: son los géneros gramaticales. Ninguna lengua carece de recursos para establecer distinciones de género (Stahlberg et al., 2007). Se denomina a este sistema clasificatorio, definido por los rasgos y categorías que sirven para marcar el género en las lenguas, "gramática de género" (Gygax et al., 2019). Así, se distingue entre masculino y femenino, o entre masculino, femenino y neutro, o, incluso, entre más géneros, como el vegetativo u otros, dependiendo de las lenguas (Boroditsky, Schmidt \& Phillips, 2003). Es decir, las lenguas varían en cuanto a cómo y cuánto marcan el género gramatical (Corbett, 1991). Un grupo mayoritario de las lenguas indoeuropeas (i.e., el español, el francés, el italiano, el portugués) son lenguas con carga de género (gender loaded) porque acarrean información de género en varias categorías gramaticales (Sera et al., 2002). En primer lugar, todos los sustantivos tienen género $\mathrm{y}$, luego, también lo tienen las palabras que deben armonizar o concordar con ellos: los pronombres, adjetivos y determinantes, y en algunas, incluso el verbo. En español o portugués, por ejemplo, los sustantivos marcan el género mediante la vocal final, /o/ para el masculino y / $/$ / para el femenino (con algunas pocas excepciones). En contraste, solo unas pocas categorías gramaticales contienen información de género en alemán, una lengua que, como el ruso, el polaco y otras más, distingue entre tres géneros: masculino, femenino y neutro. Por último, en el inglés, el coreano, el japonés, el mandarín y el turco, ningún objeto

${ }^{20}$ Estas asimetrías están presentes también en los casos en los que un mismo término aplicado a un hombre es laudatorio, pero aplicado a una mujer es peyorativo. Por ej. "él es un profesional" vs. "ella es una profesional (= prostituta)", referido por Lakoff (1973); este fenómeno es denominado por Jiménez Rodrigo, Román Onsalo y Traverso Cortes (2011) el uso de “duales-aparentes". Véase Fernández Martín (2011) para un extenso estudio de este fenómeno tanto en español como en inglés. 
inanimado posee género gramatical. Estas últimas se han denominado sistemas semánticos de género, porque el género viene determinado solo por el significado de las palabras. Por contraste, las lenguas con carga de género que extienden las distinciones de género a entidades inanimadas, deben recurrir a rasgos formales, fonológicos, morfológicos y/o sintácticos, para determinar el género para tales referentes (Beller et al., 2015). Según una taxonomía más fina, deberían reconocerse tres tipos de lenguajes: generizados (gendered), que marcan el género en nombres, pronombres y otras palabras (vgr. español, italiano, francés, hebreo); semi-genéricos o con poca carga de género, que marcan el género solo en los pronombres (vgr. inglés, sueco) y sin género (genderless), que no marcan el género ni en los sustantivos ni en los pronombres, aunque pueden tener algunas palabras que distinguen el género (vgr. finés, turco, mandarín) (Stahlberg et al., 2007). ${ }^{21}$

Ahora bien, no solo se considera arbitrario que las lenguas otorguen mayor o menor prominencia al género (Guiora et al., 2006), sino que el género gramatical asignado a las palabras tiene un lazo arbitrario con las propiedades de los objetos referidos. ${ }^{22}$ Esto es evidente en el caso de los sustantivos referidos a objetos inanimados, por lo cual proporcionan una manera de estudiar los efectos específicamente lingüísticos sobre la cognición (Vigliocco et al., 2005; Boroditsky, Schmidt \& Phillips, 2003). Así, los objetos inanimados tienen asignado solo un género, y este varía con las lenguas (i.e. "luna" es femenino en español y en ruso, pero "der Mond" es masculino en alemán; "cama" es femenino en español, pero "lit" es masculino en francés, etc.). En el caso de muchos animales, tienen asignado un único género arbitrario, p. e. "jirafa" solo

${ }^{21}$ Otra clasificación propone distinciones aún más graduales entre cinco grandes grupos de lenguas, según sean más o menos generizadas (cfr. Gygax et al., 2019).

${ }^{22}$ Se considera que el género de las palabras es arbitrario porque no tiene ninguna base semántica (Everett, 2013) o carece de significado (Boroditsky \& Phillips, 2003). Sin embargo, algunas feministas ponen en duda el origen arbitrario de estas asociaciones, mostrando que ciertos elementos que son "naturalmente" fundamentales y que gobiernan nuestra vida, como el sol, no casualmente son nombrados mediante sustantivos masculinos (Irigaray, 1993, p. 68). Seguramente esa misma sospecha llevó a Lakoff (1987) a titular su libro Women, Fire, and Dangerous Things: What Categories Reveal About the Mind, aludiendo al dyirbal, una lengua aborigen australiana que clasifica en cuatro categorías a los sustantivos, dos de ellas basadas en el sexo biológico: una clase agrupa a hombres y a la mayor parte de las entidades animadas, otra agrupa a las mujeres, algunos animales, el fuego, el agua y las cosas peligrosas. Sin embargo, el género de las palabras que refieren a la luna y el sol varía en las diversas lenguas: en alemán, por ejemplo, "sol" es femenino y "luna" masculino, y ello también produce asociaciones consistentes con el género en sus hablantes, aunque diferentes a las de otras lenguas (Konishi, 1993). 
admite género femenino y "sapo" solo masculino, en español ${ }^{23}$, aunque no hay consistencia entre las lenguas y, además, algunos animales tienen asignados dos géneros, como "perro-perra" y "gato-gata", también en español, de manera semejante a los humanos. La asignación de género tampoco es consistente en una misma lengua, si consideramos el caso de algunos hipérnimos e hipónimos (i.e. "el árbol", "la acacia").

En el contexto del debate acerca de la HRL, surge naturalmente la pregunta acerca de si las lenguas con carga de género imponen sobre sus hablantes, a través del uso obligatorio de marcadores de género, ciertas representaciones conceptuales con información de género ${ }^{24}$ cuando se refieren a entidades no sexuadas, y si ejercen, también, otras influencias sobre la memoria, la percepción de semejanzas y las descripciones de propiedades, activando y cristalizando sesgos o estereotipos de género. Esta influencia fue testeada en una temprana investigación sobre el tema referida por Jakobson (1971), en la que se constataron las asociaciones que los hablantes rusos realizaban entre los días de la semana y cierta tendencia a personificarlos mediante características masculinas o femeninas, consistente con los géneros gramaticales de los nombres respectivos: "lunes", "martes" y "jueves" son masculinos, "miércoles", "viernes" y "sábados" son femeninos en ruso. ${ }^{25}$

Así, la asignación de género no parece ser enteramente arbitraria para los hablantes de lenguas con carga de género. En efecto, resulta extraño que en otras lenguas las palabras familiares tengan un género

${ }^{23}$ Saalbach et al. (2012) primero y luego Imai et al. (2014) realizaron distintos experimentos con hablantes del alemán y el japonés, esta última sin marcadores de género, y constataron que el género gramatical asignado en alemán al nombre básico de los animales, vgr. "jirafa", afecta las inferencias que realizan los hablantes del alemán sobre las propiedades biológicas de ejemplares de esos animales, vgr. sobre esta o aquella jirafa, y que ello no ocurre en los hablantes del japonés.

${ }^{24}$ Nótese que la "información de género" a la que se hace referencia en los estudios que revisaremos a continuación abarca elementos relacionados tanto con los "roles de género" (las características y roles socialmente asignados a varones y mujeres) como con las "expresiones de género" (los nombres propios, por ejemplo). En los estudios psicolingüísticos realizados se asume implícitamente la norma social de la alineación de sexo: rol de género, identidad de género, expresión de género y orientación sexual a la que nos referimos en la Introducción, así como a la distinción binaria entre los dos géneros.

${ }^{25}$ Segal y Boroditsky (2011) estudiaron las personificaciones de ciertos conceptos abstractos realizadas en obras de arte, como por ejemplo: amor, justicia, tiempo, caridad, fama, fortuna, paz, verdad, atendiendo a las lenguas de los autores y constataron una correspondencia entre el género de dichos sustantivos en la lengua del artista y el género de las personificaciones realizadas en las obras. 
diferente al que tienen en nuestra lengua. ${ }^{26}$ En primer lugar, porque hay cierto grado de consistencia ${ }^{27}$ entre el género gramatical y el sexo biológico en el caso del femenino y el masculino cuando es aplicado a los seres humanos. ${ }^{28}$ Luego, no es difícil conjeturar que esta asociación podría generalizarse a otras palabras referidas a entidades animadas e inanimadas (Everett, 2013). De este modo, el género gramatical asignado a los sustantivos referidos a entidades no sexuadas finalmente suscitaría asociaciones conceptuales con algunos rasgos característicos del sexo biológico con el que está vinculado en el caso de las entidades sexuadas, en los usuarios de esas lenguas.

\section{Efectos cognitivos de las diferencias morfosintácticas}

Las investigaciones psicolingüísticas han explorado con distintas estrategias los vínculos entre el género de las palabras y ciertos fenómenos cognitivos. Por ejemplo, Konishi (1993) comparó las reacciones de 40 hablantes del español y 40 del alemán respecto de 54 palabras de sus respectivas lenguas nativas. La tarea consistió en ordenar esas palabras en una escala de 1 a 7 atendiendo a su "potencia", mayor o menor, asumiendo que la "masculinidad" está asociada estereotípicamente con una "potencia" mayor. Todas las palabras correspondían a entidades inanimadas, y fueron escogidas de modo que tuvieran un género opuesto en ambas lenguas, de la siguiente forma: 27 sustantivos con género masculino en español y otras tantas, sinónimas de aquellas, en alemán, pero con género femenino; las restantes 27 con género femenino en español y sus correspondientes sinónimas en alemán, con género masculino. Los sujetos desconocían el objetivo del estudio. Los resultados corroboraron la hipótesis de que el género asignado a las palabras suscitaba conceptualizaciones diferentes de las entidades nombradas. Un estudio

${ }^{26}$ Una evidencia de ello son las dificultades que se suscitan al intentar traducir nombres con distintos géneros en lenguas diferentes. Por ejemplo, el nombre de los animales en las fábulas infantiles que tienen un género diferente en la lengua a la que se traduce, ya que el cambio de género altera la personificación de los animales (cfr. Everett, 2013).

${ }^{27}$ La consistencia no es completa porque actualmente se acepta que, biológicamente hablando, no hay dos sexos, ni desde el punto de vista anatómico, ni tampoco genético (cfr. nota 4).

${ }^{28}$ Sin embargo, algunos sustantivos que usamos para hablar de los seres humanos son genéricos, en el sentido que refieren sólo a uno u otro género, el masculino o el femenino, como "mujer", "madre", padre", mientras otros en las lenguas con menos carga de género que el español pueden considerarse como neutrales, indefinidos o híbridos como "persona", "paciente", "estudiante" (Corbett, 2015). 
posterior (Flaherty, 2001) hizo un experimento similar con hablantes del español y del inglés, para estudiar de qué modo el género lingüístico podría afectar la percepción de las entidades inanimadas referidas. En este caso los hablantes debían asignar nombres y cualidades a imágenes visuales (dibujos de objetos): los resultados mostraron una amplia consistencia en asignar nombres y atributos (i.e., como la belleza o la pequeñez a nombres femeninos) conforme al género de los nombres en la propia lengua, en el caso del español, pero no así en caso del inglés. Sera et al. (1994) habían constatado un resultado similar, en un test en el que se asociaba una imagen de un objeto natural o artificial y una etiqueta, con hablantes de español e inglés, y se les pedía a los sujetos que también asignaran una voz masculina o femenina a la imagen. Los efectos se detectaron en español y no en inglés. Sera et al. (2002) constataron el mismo efecto en tests realizados con hablantes del español y el francés, no así con el alemán, lo que quizás pueda explicarse porque esa lengua distingue entre tres géneros y no dos. Estudios ulteriores, sin embargo, también constataron efectos de género en lenguas con tres géneros.

Una limitación de estos estudios es que los sujetos son testeados en su propia lengua nativa, por lo cual solo mostrarían los efectos de esa lengua sobre el pensamiento de sus hablantes, pero no efectos sobre el pensamiento en relación con el uso de otras lenguas o al realizar tareas no lingüísticas, lo que, en cambio, permitiría evaluar mejor su impacto en distintas funciones cognitivas y si este se produce o no de manera consciente (cfr. Lucy, 2016). Así, experimentos que no requieren tareas lingüísticas o que permiten comparar el impacto de diferentes lenguas sobre el pensamiento de un mismo grupo de hablantes, podrían arrojar mejores evidencias de efectos relativistas de género. Las lenguas seleccionadas en las pruebas debían diferir claramente respecto de sus gramáticas de género aunque las comunidades a las que pertenecen sus hablantes no debían diferir culturalmente, para excluir el papel de factores culturales no lingüísticos en la explicación del comportamiento de los hablantes. ${ }^{29}$

Boroditsky, Schmidt y Phillips (2003) estudiaron a dos grupos de hablantes del español y el alemán, en un experimento realizado en inglés como segunda lengua para ambos grupos, enseñándoles 24 nombres

\footnotetext{
${ }^{29}$ Deslindar los factores lingüísticos de otros rasgos culturales para explicar una diferencia cognitiva no es, sin embargo, una tarea sencilla. Véase el estudio realizado sobre una población de hablantes que comparten la misma cultura pero hablan diferentes dialectos de una misma lengua, el noruego, que difieren en sus marcadores de género, en el que se comprobaron influencias tanto culturales como lingüísticas relativas al género (cfr. Beller et al., 2015).
} 
propios asignados a 24 objetos inanimados, que correspondían en cada una de las lenguas a sustantivos comunes con diferentes géneros. La mitad de las veces el nombre propio asignado era consistente con el género del objeto nombrado en la lengua nativa y la otra mitad no lo era. El experimento buscaba testear la memoria de estos nombres propios, de uno u otro género, en relación con su asociación con objetos cuyos nombres tenían también un género asignado en esa lengua. La hipótesis que confirmaron era que cada grupo de hablantes recuerda mejor los nombres propios consistentes con el género del nombre común en la lengua nativa, por ejemplo, los hablantes del alemán recuerdan mejor "Patrick" para el término correspondiente a "manzana", "Apfel", porque es también masculino en alemán, y los hablantes del español recuerdan mejor "Patricia" para "manzana", porque éste es femenino en español. La explicación razonable es que la experiencia previa con la lengua nativa interfiere o se "entromete" en la capacidad para recordar estos nuevos pares de nombres cuando evidencian una inconsistencia en el género, trascendiendo así el fenómeno thinking for speaking.

Otro tipo de efecto del género gramatical puede verse en los rasgos estereotípicos con los que los objetos son caracterizados, los que se tornarían más salientes al representarse a dichos objetos en relación con el género que la palabra le asigna. Si el género gramatical fuera diferente, otros rasgos resultarían más salientes. Boroditsky, Schmidt y Phillips (2003) testearon hablantes nativos del español y el alemán sobre 24 nombres de objetos que poseían el género gramatical opuesto en ambas lenguas, de los cuales la mitad eran masculinos y la otra mitad femeninos, en un estudio nuevamente realizado enteramente en inglés, una segunda lengua para ambos grupos de hablantes. El test les pedía que asociaran con cada uno de esos objetos tres características que los describieran, eligiendo tres adjetivos para ello. Otro grupo de hablantes clasificaba los adjetivos escogidos, en más o menos masculinos o femeninos. Las respuestas fueron nuevamente consistentes en reflejar las asociaciones entre el género gramatical de los nombres y las cualidades asignadas a los objetos (i.e. "puente" es un sustantivo femenino en alemán y los puentes son descriptos por sus hablantes como bellos, frágiles y elegantes, pero es masculino en español, y son descriptos por sus hablantes como grandes, peligrosos, fuertes; "llave" es masculino en alemán, y las llaves son descriptas como duras, metálicas y útiles por sus hablantes, y es femenina en español, descriptas por los hispanoparlantes como doradas, intrincadas, delgadas, pequeñas).

En cuanto a los tests no lingüísticos, uno de ellos, utilizando solo dibujos y no palabras, consistió en pedirles a hablantes del español 
y el alemán que valoren la similaridad entre pares de dibujos que representaban a objetos o animales y a personas, varones o mujeres (Boroditsky, Schmidt \& Phillips, 2003). Las instrucciones fueron dadas en inglés, una segunda lengua en la que ambos grupos eran competentes. Los objetos dibujados fueron escogidos de modo que sus nombres respectivos tuvieran diferentes géneros gramaticales en cada una de las dos lenguas. Los dibujos eran comparados con dibujos de varones y mujeres biológicos. Los hablantes produjeron emparejamientos consistentes con el género gramatical asignado a los objetos respectivos en sus lenguas nativas, y ello sería evidencia de un "efecto de similaridad categorial incrementada", dado que agrupar las entidades en una misma categoría fortalece la percepción de similaridades entre ellas (Gomila, 2012).

Por último, resultan especialmente interesantes los resultados del estudio de Guiora et al. (2006), que comprueba que los niños que hablan una lengua con carga de género adquieren una identidad de género más tempranamente en el desarrollo que los niños que hablan una lengua que utiliza pocos o ningún marcador de género. Se definió como "identidad de género" a "la capacidad de los individuos para categorizarse a sí mismos como un miembro de un sexo y no del otro" (p. 292). Las lenguas testeadas fueron el hebreo, que marca el género incluso en los verbos y en los pronombres, singulares y plurales, de segunda persona, y a veces también en la primera persona; el inglés, en el que el género está marcado solo en los pronombres de tercera persona, y en algunos sufijos de unas pocas palabras, y el finés, donde el género no es significativo. Los niños de cada grupo tenían entre 16 y 42 meses de edad. Claramente, los niños que hablan hebreo aprenden a prestar atención obligada al género de quien habla y al de sus destinatarios, por lo tanto al género de sí mismos, para entender o producir una expresión lingüística, mucho antes que los niños que hablan inglés o finés. Este sería un claro ejemplo de la influencia cognitiva diferenciada de las lenguas, dependiendo de si algunos rasgos son o no obligadamente salientes para sus hablantes.

De acuerdo a estos resultados, la influencia del género gramatical se constata tanto en la atención como en la memoria (vgr. en la memoria de los nombres propios para objetos), en la percepción de similaridades y en tareas de categorización entre imágenes de objetos así como en las descripciones de los objetos, incluso cuando no se requiere el uso del lenguaje y cuando la tarea es realizada mediante instrucciones 0 con estímulos de una lengua diferente sin carga de género respecto a la nativa que sí la tiene. En todos los casos, la dificultad para suprimir la influencia del género gramatical puede considerarse evidencia del impacto del lenguaje sobre un variado rango de funciones cognitivas. De 
todo ello surge que el uso regular de una lengua con carga de género, en tanto obliga a prestar atención continua a las reglas morfosintácticas que conforman su gramática de género, genera "hábitos de pensamiento" (Reines \& Prinz, 2009), es decir, modos de pensar (prestar atención, percibir, asociar, recordar, caracterizar, inferir) que operan, dada su habitualidad, más o menos automáticamente. Sapir se refirió a este tipo de influencia del siguiente modo:

El "mundo real" está edificado, en gran medida inconscientemente, sobre los hábitos de lenguaje del grupo... Vemos, escuchamos y experimentamos de otra manera, en gran medida como lo hacemos, porque los hábitos de lenguaje de nuestra comunidad predisponen a ciertas opciones de interpretación (Sapir, 1929, p. 209; el subrayado es nuestro).

Se trata, por lo tanto, de una influencia no efímera, en el sentido de que no depende estrictamente del uso efectivo del lenguaje, sino que produce modos estables de cognición, es decir, efectos de largo plazo (Reines \& Prinz, 2009). Aunque pueden revertirse, esos efectos no desaparecen fácilmente. En este sentido, el lenguaje ejerce una influencia robusta que opera a través del tiempo e independientemente del contexto, y que se manifiesta, incluso, en tareas no lingüísticas. ${ }^{30}$ No obstante, como señala Lucy (2016), todavía debería establecerse con precisión de qué maneras y en qué medida operan los distintos efectos relativistas: "Puede haber efectos cualitativamente diferentes dependiendo de cuáles sean los aspectos del lenguaje (léxicos vs. gramaticales), de la cognición (clasificación vs. memoria), o el dominio (color vs. tiempo) en cuestión" (p. 506). En lo que respecta al género, esta precaución podría ser relevante, si se tienen en cuenta los diferentes rasgos lingüísticos involucrados, tanto léxicos como gramaticales, y la diversidad de lenguas en lo relativo a sus sistemas de género.

${ }^{30}$ Samuel et al. (2019) afirman, por el contrario, que en el caso de la gramática de género los efectos constatados dependen fuertemente del contexto y de las tareas (son más evidentes en el caso de asignación de sexo o de voz a entidades animadas o inanimadas que en otras tareas) de acuerdo a diferentes parámetros (tales como características de la población testeada, el grado de influencia del lenguaje en las pruebas, si las lenguas testeadas tienen dos o tres géneros, etc.). Sostienen, además, que existen otras hipótesis alternativas disponibles que podrían explicarlos. En cualquier caso, el meta-análisis realizado realizado por estos autores pone de relieve las dificultades metodológicas que rodean la investigación psicolingüística de la HRL, y no desacredita ni su viabilidad ni la conveniencia de explorar otras estrategias metodológicas (vgr. la propuesta por Thierry, 2016). 
En cuanto a la sugerencia de Reines y Prinz (2009) respecto a otra variedad que denominan "whorfianismo ontológico", consistente en el hecho de que agrupamos a los objetos o particulares en categorías con la ayuda de los sistemas clasificatorios provistos por las lenguas, también ocurriría en el caso del género. Las lenguas que, como la nuestra, poseen un sistema categorial exhaustivo que distingue entre dos géneros para todas las entidades, animadas e inanimadas, con lo cual apoyan la asociación de cada una de ellas con características estereotípicas para uno u otro género, producen, en conjunto, una manera peculiar de organizar la experiencia. Al poner obligatoriamente a los objetos en una misma categoría gramatical,

las lenguas pueden invitar a sus hablantes a hacer (de manera no necesariamente consciente) comparaciones que de otro modo no habrían hecho (o quizás no habrían hecho tan a menudo o con los mismos fines en mente) (...) [así] las personas pueden descubrir similitudes significativas entre los objetos [que] (...) luego son almacenadas o realzadas en las representaciones de los objetos. (Boroditsky \& Phillips, 2003, p. 932).

Luego, “...dado que estas influencias no son obvias por medio de la introspección, somos propensos a confundir los límites de las categorías lingüísticamente influenciadas con los límites que son privilegiados, naturales e inevitables" (Reines \& Prinz, 2009, p. 1029). Aquí, el lenguaje actuaría no solo como un foco sino también como un inductor de esas categorías (Wolff \& Holmes, 2011).

\section{Efectos psicológicos de la universalización del género masculino}

"El hombre es la medida de todas las cosas" ${ }^{1}$

Protágoras

Cuando escuchamos frases como la de Protágoras pensamos en un varón cis heterosexual blanco de clase media, e identificamos

\footnotetext{
${ }^{31}$ En griego antiguo hay dos palabras diferentes que suelen traducirse por "hombre" al español. "Anthropos", cuya traducción más correcta es "ser humano" y "aner" cuya traducción más fiel sería varón (i.e. ser humano de género masculino). El hecho de que la famosa frase de Protágoras se haya popularizado traduciendo "anthropos" por "hombre" es una muestra clara del sesgo de género que produce nuestra lengua al generalizar en masculino. De este tema nos ocuparemos en este apartado.
} 
este estereotipo ${ }^{32}$ como la medida de todas las cosas, de manera que todo lo que se aleja de él resulta "desviado", "impropio", "inadecuado" e incluso "patológico". Y, por supuesto, esto incluye varones trans, varones gays, personas no blancas, pobres y, desde ya, mujeres (cis y trans, lesbianas, heterosexuales, bisexuales, asexuales, blancas y no blancas, ricas y pobres). Este fenómeno se denomina la ginopia del lenguaje y consiste en "la falta de registro de la existencia de un sujeto femenino, la invisibilización de las mujeres (y otros sujetos) que quedan fuera de lo nombrado" (Maffía, 2012, p. 2; véanse también Lakoff, 1973; Irigaray, 1993 sobre la invisibilización de las mujeres, y respecto de otras identidades, Cabral, 2009). En español se ha generalizado el uso de la expresión lenguaje inclusivo (aunque en la literatura especializada también se emplea "lenguaje libre de género", "lenguaje no sexista" y "lenguaje neutral al género") (Sczesny, Formanowicz \& Moser, 2016), para hacer referencia a las distintas estrategias de uso de las expresiones de la propia lengua a las que nos referiremos enseguida, tendientes a evitar la universalización del masculino o bien a incorporar nuevas expresiones que den cuenta de la diversidad de géneros. Pero también refiere a otro tipo de cambios introducidos en el léxico e incluso en las reglas de la gramática de género, como parte de una política no sexista relativa a la lengua y también a otras dimensiones extralingüísticas (Sczesny, Formanowicz \& Moser, 2016).

Como nos recuerda Maffía, no es obvio que el uso universal de "hombre" sea realmente universal. En sus palabras:

Un caso clásico es la Declaración de los Derechos del Hombre y el Ciudadano, de la Revolución Francesa de 1789, que en su artículo $1^{\circ}$ dice: "Todos los hombres nacen y permanecen libres e iguales y tienen los mismos derechos". Esa declaración, considerada universal en su mención de los derechos del hombre y el ciudadano, solo aceptaba la ciudadanía de los varones blancos, adultos y propietarios, y solo preservaba sus derechos bajo la forma del lenguaje universal (Maffía, 2012, p. 3).

${ }^{32}$ Un estereotipo es un conjunto de rasgos que el sentido común atribuye a una persona, a sus conductas e intenciones, puesto que los considera propios o característicos de un grupo particular (vgr., los hombres, los blancos, los jóvenes) al que ella pertenece. Como afirma Talbot (2003), los estereotipos son prácticas representacionales que suponen simplificación, reducción y naturalización, permiten ordenar información social compleja, predecir e incluso prescribir la conducta esperada. 
Será por esto que el primer cambio significativo ocurrido en la búsqueda de un lenguaje más inclusivo, y que podemos calificar de exitoso, ha sido la eliminación de la palabra "hombre" para hacer referencia a los seres humanos en su conjunto. ${ }^{33}$ Hasta no hace mucho era moneda frecuente este uso; pensemos, por caso, en El hombre y la gente de Ortega y Gasset o en The Descent of Man de Darwin. En la actualidad no se publican libros nuevos con estos títulos, y se evita el uso de "hombre" como genérico para referir a nuestra especie biológica.

Este rasgo de la gramática de género consiste en usar un sustantivo de género masculino cuando se desea hacer una afirmación general. Nuestra lengua, entre muchas otras, establece que el masculino no solo se usa para referir de manera específica a uno o más varones, sino también de manera genérica o para hacer afirmaciones generales, tanto en singular como en plural, es decir, incluyendo a personas de género femenino entre los individuos referidos. La universalización del masculino se manifiesta de dos maneras diferentes. La primera, es mediante el uso de algunos sustantivos comunes masculinos ("hombre", "hijo", "padre") en singular, para hacer referencia a un conjunto de personas de género diverso (en contextos tales como el de la cita de Protágoras). La segunda, es en las afirmaciones en plural. En nuestra lengua, cuando hablamos de personas de diversos géneros, basta que haya una persona de género masculino en el grupo referido, para que deba usarse el plural en masculino. Lo mismo sucede cuando se desconoce el sexo de las personas. Así, hablamos de "los niños", "los estudiantes", "los profesores", "los diputados", etc. El plural en femenino, en cambio, solo se usa cuando la totalidad de los involucrados son de género femenino. Estas asimetrías entre el femenino y el masculino se consideran indicativas del carácter sexista de la lengua (Kaufmann \& Bohner, 2014; Koeser, Kuhn \& Sczesny, 2015). Veamos algunos efectos causados por el genérico masculino en las lenguas, revisando evidencias empíricas que muestran que la forma en la que nos referimos

${ }^{33}$ Sería falso decir que estas minorías (no nos referimos a minorías numéricas, ya que hay menos hombres cis heterosexuales blancos de clase media que personas de todos los demás grupos, sino a minorías en cuanto a su acceso al poder político, económico, social, etc.) han carecido de sustantivos y adjetivos para ser identificadas en nuestra lengua. Siempre los ha habido. Lo que resulta notable es el cambio producido en los últimos años (digamos los últimos 50 años) incorporando términos y giros no peyorativos para hacer referencia a ellas. Podríamos decir, en este sentido, que el cambio lingüístico hacia formas de lenguaje más inclusivo es un hecho, y que este cambio ha sido exitoso, al menos en algún grado y en algunos contextos (véase Rubin, Greene \& Schneider, 1994 y Pauwles, 2003). 
a las personas, p. e., a quien ocupa un cargo o rol social, ${ }^{34}$ influye en la activación de estereotipos femeninos o masculinos.

En un interesante estudio, McConnell y Fazio (1996) presentaron a personas de distinto sexo y con distintas actitudes hacia las cuestiones de género (más conservadores o más liberales) pequeñas historias en las que un personaje realizaba una cierta actividad. Dichas historias estaban narradas de alguna de las siguientes tres formas: (1) en un lenguaje masculinizado ("el empresario..." o "el albañil..."), (2) en un lenguaje claramente inclusivo ("el/la empresario/a..." o "el/la albañil..."), o (3) en un lenguaje más neutro ("la persona a cargo de la empresa..." o "quien realizaba la obra..."). ${ }^{35}$ Se pedía a los participantes que atribuyeran ciertas características a los personajes, algunas estereotípicamente masculinas como "asertivo", otras típicamente femeninas como "cálida". El resultado del estudio mostró que, más allá del género de los participantes, la lectura de textos en masculino activaba la atribución de rasgos masculinos y la versión en lenguaje claramente inclusivo, más rasgos femeninos (de una manera más marcada entre los conservadores que entre los liberales). Muchos estudios posteriores confirmaron la hipótesis de que el uso del masculino como genérico activa estereotipos y representaciones masculinas en mayor medida que el uso de formas más neutras o inclusivas, tanto en alemán (Irmen \& Rossberg, 2004; Braun et. al., 2005), como en español (Kaufmann \& Bohner, 2014). En efecto, Kaufmann y Bohner (2014) realizaron un estudio entre hablantes del español, comparando historias breves narradas alternativamente en lenguaje inclusivo ("lxs..." o "las/los...") o usando las formas masculinas para los plurales y generalizaciones. Pidieron a los lectores que pongan un nombre a los protagonistas de las historias y constataron que las formas no inclusivas llevan a pensar en protagonistas masculinos, mientras que las formas inclusivas disminuyen este sesgo androcéntri-

${ }^{34} \mathrm{El}$ caso de la falta de nombres para profesiones que hoy realizan las mujeres pero antes solo ejercían los hombres, es terreno de ardientes disputas lingüísticas que resumen algunas de las más profundas diferencias entre quienes promueven el uso de un lenguaje inclusivo. El problema que surge es si ante estos casos (por ej. policeman) el lenguaje debe reformarse buscando términos en femenino para referirse a las mujeres que ocupan determinados roles (police woman), o si, por el contrario, hay que buscar formas neutras para referirse a todos los géneros de la misma manera (police officer). Gabriel, Gygax y Kuhn (2018) las denominan estrategias de feminización y de neutralización del lenguaje, respectivamente.

${ }^{35} \mathrm{El}$ experimento se realizó en inglés con angloparlantes. Las tres condiciones correspondían a los siguientes tipos de ejemplos: (1) “chairman", (2) “chairperson", (3) "chair". Adaptamos los ejemplos a casos similares del español para hacer comprensible el trabajo realizado. 
co. Curiosamente, este efecto es más notable entre las lectoras mujeres que entre los hombres. Y también curiosamente, los términos neutros como "persona" inclinan la balanza hacia la masculinización de los protagonistas. Sobre la base de estos resultados, los autores concluyen recomendando el uso de un lenguaje que vuelva consciente la cuestión de género (gender-aware language) por ser más efectivo como propuesta inclusiva que el uso de genéricos neutros.

Biegler y Leaper (2015), por su parte, estudiaron el caso de los sesgos de género inducidos por el uso del lenguaje no inclusivo en niñas y niños. De acuerdo con sus estudios, el uso de los sustantivos y pronombres con carga de género precipitan un efecto cascada en la siguiente secuencia de fenómenos cognitivos: (1) saliencia de género, (2) categorización en géneros, (3) activación de los estereotipos de género, (4) activación de los prejuicios de género (p. 191). En la misma línea, Leaper (2014) revisa una enorme cantidad de estudios asociados a diferentes sesgos de género presentes en diversos tipos de formas lingüísticas, tanto con adultos como con niños. Ellos muestran que el uso del genérico masculino induce al oyente a imaginar que los ocupantes de los roles mencionados son hombres, invisibilizando o relegando a los personajes femeninos de las narraciones (Leaper, 2014). De manera similar, efectos del uso del genérico masculino fueron constatados por Stout y Dasgupta (2011), quienes mostraron que las mujeres en la situación de una entrevista laboral sienten menos posibilidad de pertenencia, menos motivación, menos expectativas de éxito y menos nivel de identificación con el cargo al que aspiran, cuando se dirigen a ellas usando el plural masculino que usando diversas formas de lenguaje que las incluye. Estos resultados indican que el genérico masculino no es -cognitivamente hablando- realmente neutro, sino que, por el contrario, induce a formar o activar representaciones masculinas, excluyendo mujeres y otras identidades. Sumados a las comprobaciones respecto a los efectos de los restantes rasgos morfosintácticos de género en la cognición, la idea de una reforma del lenguaje que promueva usos inclusivos e incluso modifique la regla del genérico masculino parece un camino interesante por recorrer. Veamos por qué.

\section{Más allá de los géneros: la cuestión del lenguaje inclusivo}

Como mencionamos al comienzo de este trabajo resulta inadecuado desde el punto de vista biológico sostener que hay dos sexos y también resulta inapropiado alinear la identidad de género con la expresión de género, los roles de género y la orientación sexual 
de las personas. Hoy vivimos en una sociedad que reconoce diversos alineamientos, incluso a través de la legislación; por ejemplo, en la Argentina con la ley de matrimonio igualitario (Ley 26.618) y la ley de identidad de género (Ley 26.743). Sin embargo, estas distinciones, acuñadas en el feminismo académico, no han trascendido a la sociedad en su conjunto. ${ }^{36}$ Así, se sigue asociando lo femenino con una específica realidad biológica, experiencial, social, laboral, etc. Y, por supuesto, la inversa también sucede: asociamos ciertos roles con ciertas determinaciones biológicas, por ejemplo, cuando escuchamos mencionar la palabra "presidente" pensamos en un hombre, cuando escuchamos la palabra "madre" pensamos en una mujer con características biológicas femeninas, no pensamos en una mujer-trans ni en una mujer que formó pareja con otra mujer y es madre de un bebé que nació del vientre de su pareja. Aunque las distinciones propuestas por la filosofía feminista pretenden recoger taxonomías existentes en nuestro mundo, nuestro lenguaje posee todavía pocos términos que permitan distinguir todas las combinaciones de "alineamientos" posibles, dado que continúa teniendo solo dos adjetivos: "femenino" y "masculino" y dos sustantivos: "mujer" y "hombre", es decir, solo dos géneros gramaticales para clasificar a todos los seres humanos. Dicho de otra forma, nuestra lengua impone la generización mandatoria, dicotómica y excluyente, para todas las entidades animadas e inanimadas. Como hemos intentado mostrar, este hecho lingüístico tiene distintos efectos cognitivos/psicológicos, más o menos perdurables y, agregamos ahora, socialmente perniciosos, porque van en la dirección de la perpetuación de formas patriarcales de organización social. Por todo ello, promover un lenguaje más inclusivo no es una mera cuestión teórica.

Mucho trabajo empírico alertó sobre la exclusión que el uso del genérico "hombre" producía en los lectores (por ejemplo Schneider \& Hacker, 1973), dando sustento a la promoción de formas más inclusivas del lenguaje. En relación con el uso del género masculino para el plural, el argumento feminista clásico ha sido que invisibilizan a las mujeres (Lakoff, 1973; Irigaray, 1993; Maffía, 2012), pero a ello se agrega que también lo hacen con todas las otras identidades de género que no se acomodan al patrón binario (Cabral, 2009). En los últimos años

\footnotetext{
${ }^{36}$ Se han elaborado una serie de categorías para trazar estas distinciones, que en algunos casos han trascendido a la población en general (por ejemplo, los términos "bisexual", "poliamor"), en otros casos, eso no ha ocurrido (como la distinción "cis" vs. "trans-", o el término "asexual"). Por otra parte, el lenguaje cotidiano siempre ha contado con términos, en general peyorativos, para referirse a las disidencias sexuales y/o de género.
} 
se han multiplicado las guías aprobadas por instituciones estatales, gubernamentales, educativas, de organizaciones sociales, etc., que indican cómo evitar ambas formas de universalización del masculino. Usualmente incluyen recomendaciones que fomentan el reemplazo de ciertas "frases hechas" y de alta frecuencia en nuestra lengua, por otras menos frecuentes pero tan gramaticalmente correctas como las primeras, mediante las cuales se busca eliminar ciertos resabios de la cultura patriarcal. Así, por ejemplo, si en un libro de historia podíamos encontrar años atrás la frase "Los nómades se trasladaban de un lado al otro con sus pertenencias, sus mujeres y sus hijos", hoy pediríamos una versión que no considere a las mujeres y los niños como propiedad privada de los hombres, tal como "Las familias nómades se trasladaban de un lado al otro con todas sus pertenencias" (ej. tomado de Bengoechea, s.f.). Sin duda, se trata de cambios que no son costosos lingüísticamente hablando, ya que no suponen cambiar la gramática del español, sino que solo requieren de una reflexión por parte del hablante o escritor acerca de algunos supuestos que operan detrás de ciertas expresiones frecuentes, que lo motive a hacer un uso menos sexista, patriarcal y/o androcéntrico del lenguaje. ${ }^{37}$ Es decir, se trata de cambios que pueden producirse mediante un esfuerzo consciente de los hablantes, apoyados por una fuerte sanción social para quienes no los incorporen a sus prácticas lingüísticas. Entre ellos, como dijimos, usar términos que no se refieran a colectivos generalizando un término que se refiere en primer lugar sólo a los varones, siempre que sea posible ("los seres humanos", "las personas" o "la gente" en lugar de "los hombres"); usar el sustantivo abstracto en lugar del plural en masculino ("el alumnado" en lugar de "los alumnos", "la presidencia" en lugar de "el presidente"). Ahora bien, estos cambios, así como aquellos que derivan del enriquecimiento léxico con nuevas categorías, no suponen un cambio en la gramática de género de la lengua sino que, simplemente, aprovechan los recursos léxicos de la lengua -los actuales o los incorporados recientemente- para describir la realidad plural con la que de hecho nos encontramos, en términos

${ }^{37}$ Que el uso del lenguaje sea "androcéntrico" supone poner en el centro al hombre e invisibilizar a la mujer. En el ejemplo mencionado, el agente que realiza la acción y del que se habla en el libro de historia son "los hombres". Que sea "patriarcal" supone reproducir lingüísticamente los supuestos de un régimen social patriarcal, en este caso, la idea de que los hombres son "dueños" de sus mujeres e hijos. Que sea "sexista" supone la superioridad del hombre sobre la mujer, en este caso serían los hombres quienes toman las decisiones y las mujeres, meramente pasivas, serían trasladadas, como cualquier otro objeto, sin exhibir voluntad propia. 
menos sexistas, patriarcales y/o androcéntricos. Hay otros cambios, sin embargo, que buscan alterar la gramática de la lengua.

En efecto, con el fin de evitar la exclusión lingüística de múltiples minorías se ha alentado la propuesta conocida como lenguaje inclusivo $^{38}$ que, como dijimos, supone realizar cambios no solo en el uso sino también cambios más profundos en el léxico e incluso en la gramática misma de la lengua. Esta propuesta requiere una reforma radical de nuestros modos de hablar, por cuanto supone violar las reglas gramaticales de género que están institucionalizadas y a las que nos hemos habituado desde que aprendimos la lengua. Hay dos formas de hacerlo. La propuesta más conservadora consiste en la visibilización de las mujeres a través de la yuxtaposición de las generalizaciones en masculino y femenino. En este caso se prefiere el uso de "las y los" para destacar la presencia de ambos, mujeres y hombres, rechazando la regla del genérico masculino. Así, en lugar de decir "los amigos" diríamos "los amigos y las amigas" o bien "los/las amigos/as" o "las/os amigas/ os". Nótese que solo la primera propuesta es fácilmente pronunciable, mientras las otras dos solo pueden funcionar en la modalidad escrita, lo que constituye una severa limitación para su generalización en los contextos comunicativos cotidianos que son predominantemente orales. Esta propuesta, sin embargo, ha sido considerada insatisfactoria, porque invisibiliza a otros géneros: no binarios, trans, intersex, etc. (Cabral, 2009). La propuesta más radical, entonces, es reformar la gramática del español, generando la forma neutra. Dado que nuestra lengua incluye una fuerte carga de género que afecta los sustantivos, adjetivos, artículos y pronombres, la reforma propuesta es muy profunda. La búsqueda de la forma adecuada de expresar el neutro ha llevado a considerar cuatro opciones: el uso de la @, de la x, del asterisco *, y de la /e/. En todos los casos, la propuesta consiste en reemplazar todas las terminaciones de palabras que denoten género introduciendo neologismos neutros, p.e., en el caso de los artículos, "1@s", "l*s", "lxs" o "les", con el objeto de desmontar la dicotomía masculino-femenino y ser explícitos en la inclusión de todas las identidades de género. Es importante notar que solo la última opción es fonéticamente posible, es decir, que si se busca arraigar dicha modificación en el lenguaje oral, solo esta opción (u otra similar) es viable. ${ }^{39}$

${ }^{38}$ Se entiende que un lenguaje es inclusivo si no es androcéntrico, ni sexista ni patriarcal. Pero no hay una propuesta unánime acerca de qué forma debería tomar este lenguaje exactamente, es decir, qué rasgos gramaticales y relativos al uso se requerirían. En lo que sigue mencionaremos algunas alternativas.

${ }^{39}$ Véase Pauwles (2003) como repaso de las diversas estrategias para dar forma 
Detrás de estas diversas reformas del español hacia un lenguaje más inclusivo, hay propuestas teóricas alternativas o formas alternativas de "ver el mundo" que buscan una vehiculización lingüística. De alguna manera, se trata de la HRL vista del revés: distintos grupos humanos que "ven el mundo" de formas diferentes buscan que el lenguaje exprese de la manera más perspicua posible esa forma de "ver el mundo". Claramente algunas de estas opciones implican reformas radicales de la lengua. Y no está claro que ese tipo de cambios lingüísticos puedan producirse solo por la suma de voluntades individuales o por el impulso sostenido de colectivos conscientes de su importancia cultural. Sin embargo, insistir en el uso del lenguaje inclusivo, aun alterando las reglas gramaticales actuales, produce en los oyentes/lectores un efecto cognitivo también. Davidson (1990) sostuvo que las metáforas son como golpes en la cabeza: producen efectos cognitivos a pesar de ser afirmaciones o bien triviales o bien carentes de sentido (dado que, según este autor, no existe un "significado metafórico" sino que las palabras solo tienen significados literales que generan sinsentidos al combinarse de las maneras en las que se combinan en las metáforas). Esta disrupción de las reglas de la lengua (semánticas o pragmáticas en el caso de Davidson) que suponen las metáforas, produce un efecto similar a un golpe en la cabeza, por cuanto nos lleva a pensar de maneras diferentes a las habituales. Mientras seguimos debatiendo acerca de cuál sería la mejor reforma del lenguaje, el uso de las formas lingüísticas que violan las reglas del español puede producir en los oyentes un efecto similar al de las metáforas. Es claro que si, finalmente, las nuevas reglas de un lenguaje inclusivo se impusieran, ello no bastaría para generar una sociedad más inclusiva. Pero estos golpes en la cabeza pueden generar no solo efectos lingüísticos sino cognitivos e incluso afectivos, alterando nuestros hábitos de pensamiento, actitudes y acciones. Tal vez estos usos violatorios del lenguaje nos lleven a pensar en la necesidad de volver más inclusiva a nuestra sociedad. Y si esto ocurre, el lenguaje inclusivo habrá tenido el efecto que sus defensores buscaban. Y resulta claro, por los argumentos que presentamos a lo largo del trabajo, que perpetuar las formas lingüísticas heredadas en lo relativo al género contribuye a perpetuar formas de organización social que queremos cambiar. $^{40}$

al lenguaje no sexista en diferentes lenguas y teniendo en cuenta diferentes razones.

40 Agradecemos las valiosas observaciones y sugerencias hechas por quienes evaluaron nuestro trabajo, por cuanto nos han permitido mejorarlo en diversos aspectos, así como los comentarios realizados por quienes forman parte del grupo SADAFFEM, donde lo presentamos previamente. 


\section{Bibliografía}

Acero, J. J. (1998). Introducción: Concepciones del Lenguaje. En Enciclopedia Iberoamericana de Filosofía, Filosofía del Lenguaje I, Semántica (pp. 11-25). Trotta.

Beauvoir, S. de (1998). El segundo sexo. Cátedra.

Beller, S., Bratebo, K. F., Lavik, K. O., Reigstad, R. D., \& Bender, A. (2015). Culture or language?: What drives effects of gramatical gender. Cognitive Linguistics, 26(2), 331-359.

Bengoechea, M. (s.f.). Guía para la revisión del lenguaje desde la perspectiva de género. Comisión NOMBRA, Instituto de la Mujer. Recuperado el 26/1/20 de https://shorturl.at/pAKY3

Biegler, R., \& Leaper, C. (2015). Gendered language: Psychological principles, evolving practices, and inclusive policies. Policy Insights from Behavioral and Brain Sciences, 2(1), 187-194.

Bloom, P., \& Keil, F. C. (2001). Thinking through Language. Mind \& Language, 16, 351-367.

Boroditsky, L., \& Phillips, W. (2003). Can quirks of grammar affect the way you think? Spanish and German speakers'cis ideas about the genders of objects. En R. Alterman \& D. Kirsh (Eds.), Proceedings of the 25th Annual Meeting of the Cognitive Science Society (pp. 928-933). Cognitive Science Society.

Boroditsky, L., Schmidt, L., \& Phillips, W. (2003). Sex, Syntax and Semantics. En D. Gentner \& S. Goldin-Meadow (Eds.), Language in mind: Advances in the studies of language and cognition (pp. 61-79). The MIT Press.

Bossong, G. (2009). The typology of Tupi-Guarani as reflected in the grammars of four jesuit missionaries. Historiographia Linguistica, $36(2 / 3), 225-258$.

Braun, F., Sczesny, S., \& Stahlberg, D. (2005). Cognitive effects of masculine generics in German: An overview of empirical findings, Communications, 30, 1-21.

Cabral, M. (2009). Interdicciones: Escrituras de la intersexualidad en castellano. Anarrés.

Corbett, G. G. (1991). Gender. Cambridge University Press.

Corbett, G. G. (2015). Hybrid nouns and their complexity. En J. Fleischer, E. Rieken, \& P. Widmer (Eds.), Agreement from a diachronic perspective. De Gruyter Mouton. https://doi.org/10.1515/9783110399967

Davidson, D. (1990). Qué significan las metáforas. En De la verdad y la interpretación. Gedisa.

Eckert, P., \& McConnell-Ginet, A. R. (2003). Language and gender. 
Cambridge Textbooks in Linguistics. Cambridge University Press. Evans, N., \& Levinson, S. (2009). The myth of language universals: Language diversity and its importance for cognitive science. Behavioral and Brain Sciences, 32, 429-492.

Everett, G. (2013). Linguistic relativity: Evidence across languages and cognitive domains. De Gruyter Mouton.

Fausto-Sterling, A. (1993). The five sexes. The Sciences, 33(2), 20-24.

Fausto-Sterling, A. (2000). Sexing the body. Basic Books.

Fernández Martín, C. (2011). Comparing sexist expressions in English and Spanish: (De)constructing sexism through language. ES. Revista de Filología Inglesa, 32, 67-90.

Flaherty, M. (2001). How a language gender system creeps into perception. Cross-cultural Psychology, 32(1), 18-31.

Gabriel, U., Gygax, P., \& Kuhn, E. (2018). Neutralizing linguistic sexism: Promising, but cumbersome? Group Processes \& Intergroup Relations, 21(5), 844-858.

Gentner, D., \& Goldin-Meadow, S. (2003). Whither Whorf. En D. Gentner $\&$ S. Goldin-Meadow (Eds.), Language in mind: Advances in the study of language and thought (pp. 3-14). The MIT Press.

Gomila, A. (2012). Verbal minds: Language and the architecture of cognition. Elsevier.

Gordon P. (2010). Worlds without words: Commensurability and causality in language, culture, and cognition. En B. Malt \& P. Wolff (Eds.), Words and the mind: How words capture human experience (pp. 199-218). Oxford University Press.

Guiora, A., Beit Hallahmi, B., Fried, R., \& Yoder, C. (2006). Language environment and gender identity attainment. Language Learning, 32(2), 289-304.

Gumperz, J. J. \& Levinson, S. C. (1996). Introduction: Linguistic relativity re-examined. En J. J. Gumperz \& S. C. Levinson (Eds.), Rethinking linguistic relativity (pp. 1-18). Cambridge University Press.

Gygax, P. M., Elminger, D., Zufferey, S., Garnhan, A, Sczesny, S., von Stockhausen, L., Braun, F., \& Oakhill, J. (2019). A language index of grammatical gender dimensions to study the impact of grammatical gender on the way we perceive women and men. Frontiers in Psychology, 10, 1604. https://doi.org/10.3389/ fpsyg.2019.01604

Hellinger, M., \& Bußmann, H. (2001). Gender across languages: The linguistic representation of women and men. En M. Hellinger \& H. Bußmann (Eds.), Gender across languages: The linguistic representation of women and men (pp. 1-26). John Benjamin. 
Imai, M., Schalk, L., Saalbach, H., \& Okada, H. (2014). All giraffes have female-specific properties: Influence of grammatical gender on deductive reasoning about sex-specific properties in German speakers. Cognitive Science, 38, 514-536.

Irigaray, L. (1993). Je, tu, nous: Toward a culture of difference. Routledge. Irmen, L., \& Rossberg, N. (2004). Gender markedness of language: The impact of grammatical and nonlinguistic information on the mental representation of person information. Journal of Language and Social Psychology, 23, 272-307.

Jakobson, R. (1971). On linguistic aspects of translation. En Selected writings, Vol. II (pp. 260-266). Mouton.

Jiménez Rodrigo, M.L., Román Onsalo, M., \& Traverso Cortes, J. (2011). Lenguaje no sexista y barreras a su utilización: Un estudio en el ámbito universitario. Revista de Investigación en Educación, 9(2), 174-183.

Kaufmann, C., \& Bohner, G. (2014). Masculine generics and genderaware alternatives in Spanish. IZGOnZeit. Online zeitschrift des Interdisziplinären Zentrums für Geschlechterforschung (IZG), 8-17. https://doi.org/10.4119/izgonzeit-1310

Koeser, S., Kuhn, E. A., \& Sczesny, S. (2015). Just reading? How genderfair language triggers readers' use of gender-fair forms. Journal of Language and Social Psychology, 34(3), 343-357. https://doi. org/10.1177/0261927X14561119

Konishi, T. (1993). The semantics of grammatical gender: A cross-cultural study. Journal of Psycholinguistic Research, 22, 519-534.

Lakoff, G. (1987). Women, fire, and dangerous things: What categories reveal about the mind. University of Chicago Press.

Lakoff, R. T. (1973). Language and woman's place. Language in Society, $2(1), 45-80$.

Lamas, M. (1986). La antropología feminista y la categoría "género". Nueva Antropología, 8(30), 173-198.

Leaper, C. (2014). Gender similarities and differences in language. En T. M. Holtgraves (Ed.), The Oxford handbook of language and social psychology. Oxford University Press.

Lucy, J. A. (1992). Grammatical categories and cognition: A case study of the linguistic relativity hypothesis. Cambridge University Press.

Lucy, J. A. (1996). The scope of linguistic relativity: An analysis and review of empirical research. En J. J. Gumperz \& S. C. Levinson (Eds.), Rethinking linguistic relativity (pp. 37-69). Cambridge University Press.

Lucy, J. A. (2016). Recent advances in the study of linguistic relativity 
in historical context: A critical assessment. Language Learning, 66, 487-515.

Maffía, D. (2003). Contra las dicotomías: Feminismo y epistemología crítica. Seminario de Epistemología Feminista. Recuperado el 28-5-2020 de http://dianamaffia.com.ar/archivos/Contra-las-dicotom\%C3\%ADas.-Feminismo-y-epistemolog\%C3\%ADa-cr\%C3\%ADtica.pdf

Maffía, D. (2012, 2 y 3 de agosto). Hacia un lenguaje inclusivo: ¿Es posible? Presentación en las Jornadas de actualización profesional sobre traducción, análisis del discurso, género y lenguaje inclusivo, Universidad de Belgrano, 2 y 3 de agosto de 2012. Recuperado de http://dianamaffia.com.ar/archivos/Traducción-y-lenguaje-inclusivo.pdf

Malt, B. C., \& Wolff, P. (Eds.), Words and the mind: How words capture human experience. Oxford University Press.

Mannheim, B. (1982). Person, number and inclusivity in two andean languages. Acta Linguistica Hafniensia, 17(2), 139-156.

McConnell, A. R., \& Fazio, R. H. (1996). Women as men and people: Effects of gender-marked language. Personality and Social Psychology Bulletin, 22, 1004-1013. https://doi.org/10.1177/01461672962210003

Papafragou, A., Hulbert, J., \& Trueswell, J. (2008). Does language guide event perception? Evidence from eye movements. Cognition, 1081, $55-184$.

Pauwles, A. (2003). Linguistic sexism and feminist linguistic activism. En J. Holmes \& M. Meyerhoff (Eds.), The handbook of language and gender (pp. 550-570). Blackwell. https://doi. org/10.1002/9780470756942

Pinker, S. (1999). El instinto del lenguaje. Alianza.

Pinker, S. (2007). The stuff of thought: Language as a window into human nature. Penguin.

Reines, M. F., \& Prinz, J. (2009). Reviving Whorf: The return of linguistic relativity. Philosophy Compass, 4(6), 1022-1032.

Rubin, D. L., Greene, K., \& Schneider, D. (1994). Adopting genderinclusive language reforms: Diachronic and synchronic variation. Journal of Language and Social Psychology, 13, 91-114. https:// doi.org/10.1177/0261927X94132001

Saalbach, H., Imai, M., \& Schalk, L. (2012). Grammatical gender and inferences about biological properties in German-speaking children. Cognitive Science, 36, 1251-1267.

Samuel, S., Colet, G., \& Eacott, M. J. (2019). Grammatical gender and linguistic relativity: A systematic review. Psychonomic Bulletin \& Review, Theoretical Review, 26(6), 1767-1786. 
Sapir, E. (1929). The status of linguistics as a science. Language, 5(4), 207-214.

Schipper, M. (2010). Never marry a woman with big feet: Women in proverbs from around the world. Leiden University Press.

Schneider, J. W., \& Hacker, S. L. (1973). Sex role imagery and use of the generic "man" in introductory texts: A case in the sociology of sociology. The American Sociologist, 8(1), 12-18.

Scotto, C. (2020). El lenguaje humano: ¿Una estructura más un código o un sistema comunicativo dinámico, multimodal y semióticamente heterogéneo? Análisis. Revista de investigación filosófica, 7(1), 3-29.

Sczesny, S., Formanowicz, M., \& Moser, F. (2016). Can gender-fair language reduce stereotyping and discrimination? Frontiers in Psychology, 7, 25. https://doi.org/10.3389/fpsyg.2016.00025

Segal, E., \& Boroditsky, L. (2011). Grammar in art.Frontiers in Psychology, 1, 244. https://doi.org/10.3389/fpsyg.2010.00244

Sera, M., Berge, C. \& del Castillo Pintado, J. (1994), Grammatical and conceptual forces in the attribution of gender by English and Spanish speakers. Cognitive Development, 9, 261-292.

Sera, M., Elief, C., Forbes, J., Burch, M. C., Rodriguez, W., \& Dubois, D. P. (2002). When language affects cognition and when it does not: an analysis of grammatical gender and classification. Journal of Experimental Psychology: General, 131, 377-397.

Slobin, D. (1996). From 'Thought and Language' to 'Thinking for Speaking'. En J. J. Gumperz \& S. C. Levinson (Eds.), Rethinking linguistic relativity (pp. 70-96). Cambridge University Press.

Stahlberg, D., Braun, F., Irmen, L., \& Sczesny, S. (2007). Representation of the sexes in language. En K. Fiedler (Ed.), Frontiers of social psychology. Social communication (pp. 163-187). Psychology Press.

Stout, J., \& Dasgupta N. (2011). When he doesn't mean you: Genderexclusive language as ostracism. Personality and Social Psychology Bulletin, 36(6), 757-769.

Talbot, M. (2003). Gender stereotypes: Reproduction and challenge. En J. Holmes \& M. Meyerhoff (Eds.), The handbook of language and gender (pp. 468-486). Blackwell.

Thierry, G. (2016). Neurolinguistic relativity: How language flexes human perception and cognition. Language Learning, 66, 690-713.

Vigliocco, G., Vinson, D., Paganelli, F., \& Dworzinsky, K. (2005). Grammatical gender effect on cognition: Implications for language learning and language use. Journal of Experimental Psychology: General, 134(4), 501-520.

Winawer, J., Witthoft, N., Frank, M. C., Wu, L., Wade, A. R., \& Boroditsky, 
L. (2007). Russian blues reveal effects of language on colour discrimination. PNAS, 104(19), 7780-7785.

Wolff, P., \& Holmes, K. (2011). "Linguistic relativity", WIREs Cognitive Science, 2(3), 253-265. https://doi.org/10.1002/wcs.104

Wolff, P., \& Malt, B. C. (2010). The language-thought interface: An introduction. En Malt, B. C. \& Wolff, P. (Eds.), Words and the mind: How words capture human experience (pp. 3-15). Oxford University Press.

Whorf, B. L. (1956). Language, thought and reality. (J. B. Carroll, Ed.). The MIT Press.

Zlatev, J., \& Blomberg, J. (2015). Language may indeed influence thought. Frontiers in Psychology, 31(6), 1631.

Recibido el 5 de febrero de 2020, revisado el 6 de mayo de 2020, aceptado el 30 de mayo de 2020. 